일반논문-11-16-4-07

$$
\begin{gathered}
\text { 패리티 요구량 예측을 이용한 적응적 경판정 출력 기반 고속 분산 } \\
\text { 비디오 복호화 기술 }
\end{gathered}
$$

심 혁 재 ${ }^{a)}$, 오 양 근 ${ }^{a)}$, 전 병 우 ${ }^{\natural}$

\title{
Adaptive Hard Decision Aided Fast Decoding Method using Parity Request Estimation in Distributed Video Coding
}

\author{
Hiuk Jae Shim ${ }^{\mathrm{a})}$, Ryanggeun $\mathrm{Oh}^{\mathrm{a})}$, and Byeungwoo $\mathrm{Jeon}^{\mathrm{a})^{\ddagger}}$ \\ 요 약
}

분산 비디오 압축 기술은 부호화기의 복잡한 과정을 복호화기로 이동시킴으로써 저복잡도 부호화기를 가능하게 한다. 하지만 $\mathrm{WZ}$ 복호화기는 움직임 예측/보상 과정뿐만 아니라 채널 복호 과정까지 수행하기 때문에 복호화 과정의 높은 복잡도가 문제점으로 지적되 고 있다. LDPC 부호의 복호화는 상당히 반복적인 과정으로 수행되기 때문에 그 수행 횟수만큼 복잡도가 늘어나는데, 실제로 이러한 반복적인 복호 과정은 전체 $\mathrm{WZ}$ 복호화 복잡도의 $60 \%$ 이상을 차지하고 있기 때문에 복잡도 절감의 주요 대상이다. 따라서 이러한 복 잡도 절감을 위해 과거에 $\mathrm{HDA}$ (Hard Decision Aided) 방법을 적용하는 방법이 제안되었다. HDA 방법은 해당 패리티에 대한 복호 과 정의 복잡도를 상당량 줄여주지만, 채널 복호가 성공하기에 부족한 패리티량에 대해서도 여전히 복호 과정을 수행하는 문제점을 가지 고 있다. 따라서 이러한 소모적인 과정을 줄임으로써 추가적인 복잡도 절감 효과를 얻을 수 있다. 이에 본 논문에서는 비트 플레인 간 의 상관도와 시간적 상관도에 기반하여 최소 연산으로 패리티 요구랑을 예측하는 방법을 제안한다. 제안 방법과 HDA 방법을 함께 적 용할 경우 채널 복호 과정에서는 평균 $72 \%$ 정도의 고속 복호가 가능하며, 저하되는 율 왜곡 성능은 $-0.0275 \mathrm{~dB}$ (BDPSNR) 정도로 상당히 낮다.

\begin{abstract}
In distributed video coding, low complexity encoder can be realized by shifting encoder-side complex processes to decoder-side. However, not only motion estimation/compensation processes but also complex LDPC decoding process are imposed to the Wyner-Ziv decoder, therefore decoder-side complexity has been one important issue to improve. LDPC decoding process consists of numerous iterative decoding processes, therefore complexity increases as the number of iteration increases. This iterative LDPC decoding process accounts for more than $60 \%$ of whole WZ decoding complexity, therefore it can be said to be a main target for complexity reduction. Previously, HDA (Hard Decision Aided) method is introduced for fast LDPC decoding process. For currently received parity bits, HDA method certainly reduces the complexity of decoding process, however, LDPC decoding process is still performed even with insufficient amount of parity request which cannot lead to successful LDPC decoding. Therefore, we can further reduce complexity by avoiding the decoding process for insufficient parity bits. In this paper, therefore, a parity request estimation method is proposed using bit plane-wise correlation and temporal correlation. Joint usage of HDA method and the proposed method achieves about $72 \%$ of complexity reduction in LDPC decoding process, while rate distortion performance is degraded only by $-0.0275 \mathrm{~dB}$ in BDPSNR.
\end{abstract}

Keyword : Wyner-Ziv, Fast LDPC decoding, HDA method, Parity request estimation 


\section{I. 서 론}

분산 비디오 압축 기술은 경량화 비디오 부호화를 위한 새로운 방법으로 주목을 받으면서, Stanford Univ. ${ }^{[1]}$ 와 U.C. Berkeley ${ }^{[2]}$ 에서 제안한 두 가지 구조를 중심으로 개발되고 있다. 특히, 최근에는 유럽의 DISCOVER 프로젝트의 일환 으로 Stanford Univ.의 제안 방식인 Wyner-Ziv(WZ) 비디 오 부호화 구조를 기반으로 한 연구가 활발히 진행되었다 ${ }^{[3]}$. Wyner-Ziv 비디오 부호화 방식은 입력 영상을 Key 프 레임과 WZ 프레임으로 나눈 후 Key 프레임은 H.26x 등 기존의 인트라 부호화 방식으로, WZ 프레임은 SlepianWolf 방식으로 부호화하는 특징을 갖는다. Slepian-Wolf 부호화는 입력영상을 DCT 변환과 양자화 수행 후 Turbo 코드나 LDPC 코드 등으로 채널 부호화하는데 ${ }^{[6]}$, 특히 $\mathrm{LDPC}$ 코드를 개량하여 전송률을 적응적으로 조절할 수 있 도록 설계한 LDPCA 코드를 사용하고 있다 ${ }^{[4]}$. 복호화기는 현재(t)의 WZ 프레임의 복호화를 위해, 전송받은 앞 $(\mathrm{t}-1)$, 뒤 $(\mathrm{t}+1)$ 두 장의 Key 프레임에 MCTI (Motion Compensated Temporal Interpolation)를 적용하여 보조 정보(side information)를 생성하고 ${ }^{[5]}$, 전송받은 패리티를 이용하여 보 조 정보의 에러를 정정하는 방식으로 영상을 복원한다. Wyner-Ziv 구조의 특징 상 피드백(feedback) 채널을 이용 하는데, 이는 복호화기에서 생성된 보조 정보와 원본에 발생한 잡음의 정도를 알 수 없기 때문에 소량의 패리티 를 점진적으로 전송받아 채널 복호화 과정을 수행한 후, 에러 정정 결과에 따라 패리티를 계속 전송받을 지, 혹은 전송을 중단할 지를 결정한다. 따라서 Wyner-Ziv 구조에 서의 피드백 채널의 사용은 필수적이다. 현재 분산 비디 오 압축 기술의 율 왜곡 성능은 H.264/AVC 인트라와 인 터 부호화 사이에 위치하고 있기 때문에, 아직 성능 향상 의 여지가 상당히 남아있다미.

이외에 분산 비디오 압축 기술에서 문제점으로 인식되고

a) 성균관대학교 정보통신공학부

School of Information and Communication Engineering. Sungkyunkwan University

‡ 교신저자 : 전병우 (bjeon@skku.edu)

※ 이 논문은 2010 년도 정부(교육과학기술부)의 재원으로 한국연구재단의 지원 을 받아 수행된 기초연구사업 연구임(No. 20100008030)

- 접수일(2011년3월31일),수정일(2011년6월22일), 게재확정일(2011년6월23일)
있는 부분은 복호화 과정의 복잡도라 할 수 있다. 분산 비디 오 압축 기술의 부호화 과정은 H.264/AVC 인트라 부호화 과정보다 $40 \%$ 정도 더 낮은 복잡도를 가지는 반면, 복호 화 과정은 H.264/AVC 인트라 부호화 과정 대비 약 420배 정도의 높은 복잡도를 가지며, H.264/AVC 인트라 부호화 과정에 대해 비교하더라고 여전히 25 배 정도의 높은 복잡 도를 가지고 있다 ${ }^{[8]}$. 따라서 분산 비디오 압축 기술은 현 재의 율 왜곡 성능을 최대한 유지하면서 복잡도를 낮추는 연구가 해결해야할 숙제로 남아 있다. 이렇게 높은 복잡 도가 복호화 과정에서 요구되는 큰 이유는 움직임 예측/ 보상 과정과 채널 복호 과정을 모두 복호화기에서 수행하 기 때문이다. 이 중 채널 복호 과정은 $\mathrm{LDPC}$ 부호를 사용 한 경우 전체 복잡도의 $60 \sim 70 \%$ 까지 차지하고 있기 때문 에 채널 복호의 고속화는 복잡도 감소를 위한 가장 중요 한 요소라 할 수 있다. 채널 복호의 고속화를 위한 알고리 듬은 이미 채널 부호 분야에서 여러 가지가 소개되어 있 다. 그 중 경판정 출력을 이용한 고속화 방법, 즉, $\mathrm{HDA}$ (Hard Decision Aided) 방법은 반복적인 복호 과정을 포함 하고 있는 분산 비디오 복호화 과정에 적용하기가 용이하 다. 하지만 $\mathrm{HDA}$ 방법은 영상에 따라 파라미터를 적응적 으로 적용해야 하는 문제점이 걸림돌로 남아 있었다. [9] 에서는 이러한 문제점을 해결하여 $\mathrm{HDA}$ 을 적응적으로 활 용할 수 있는 방법을 제안하였다. HDA 방법 외에 고속화 를 실현할 수 있는 방법으로는 패리티 요구량을 예측하여 불필요한 복호 과정을 줄이는 것이다. 패리티 요구량에 대한 예측은 엔트로피 계산을 통해 가능하지만, 최소의 연산을 통해 예측할 수 있는 한 가지 방법은 현재 신호가 가지는 상관도를 이용하는 것이라 할 수 있다. 따라서 본 논문에서는 $\mathrm{HDA}$ 방법을 이용하며, 동시에 현재 신호의 시간적 상관도와 비트 플레인 간에 존재하는 상관도에 기 반, 패리티 요구량을 예측하여 시간 절감율을 높이는 알고 리듬을 제안한다.

본 논문의 구성은 다음과 같다. II장에서 LDPCA 복호 과정과 $\mathrm{HDA}$ 방법에 대하여 설명하고, $\mathrm{III}$ 장에서는 패리티 요구량을 예측 하는 방법에 대해 소개한 후, 제안 방법을 설명한다. 이후 IV장의 실험 부분에서는 기존 방법 대비 실 험결과를 보이고, 마지막으로 V장에서 결론을 맺는다. 


\section{LDPCA 복호 및 HDA 방법}

\section{LDPCA 복호 과정}

LDPCA 코드 ${ }^{[4]}$ 는 Varodayan 등에 의해서 제안되었으며, $\mathrm{LDPC}$ 로 생성된 패리티를 복호화기에서 요청하는 만큼 적 응적 전송이 가능하도록 설계되었다. $\mathrm{LDPCA}$ 코드는 $\mathrm{LDPC}$ 부호화기에서 생성된 각각의 패리티를 누적(accumulation)하여 누적 코드를 부분적으로 전송하는 구조를 가 진다. 따라서 실제로 LDPCA 코드는 Turbo 코드에서 펑처 링(puncturing)하여 전송하는 것과 같은 효과를 가진다. 현 재 QCIF 영상에 대해 사용하고 있는 LDPCA 코드는 1584 비트의 길이를 가지며, 24 비트씩 66회로 나누어 전송한다. 따라서 1 회의 전송 요청 당 전체 대비 $1.5 \%$ 정도의 패리티 를 보낸다.

$\mathrm{LDPC}$ 코드 복호의 첫 번째 과정은 채널의 $\mathrm{LLR}(\mathrm{Log} \mathrm{Li}-$ kelihood Ratio) 값을 계산하는 것이며, 이 값을 LDPC 복호 기에 연판정 입력(soft input)으로 넣어준다. 내부적으로는 이를 기반으로 belief propagation의 과정을 통해 여러 번의 반복 계산으로 최종적인 연판정 출력(soft output) 값을 계 산한다. 연판정 입력인 LLR 값은 다음과 같이 계산된다.

$$
L L R=\log \left\{\frac{p(x=0 \mid Y)}{p(x=1 \mid Y)}\right\}
$$

여기서 $\mathrm{p}(\mathrm{x}=0 \mid \mathrm{Y})$ 는 보조 정보 $\mathrm{Y}$ 가 주어졌을 경우 채널 복호화된 현재 $\mathrm{x}$ 가 0 일 조건 확률을 의미한다. 따라서 이렇 게 최초로 입력한 LLR 값을 기반으로 LDPC 복호화기가 에러 정정을 수행하기 때문에 정확한 LLR 값 계산은 복호 화 과정에서 상당히 중요하다. $\mathrm{LDPC}$ 복호화기는 전송받은 패리티를 이용하여 복호화를 수행하고, 그 결과인 연판정 출력을 이용하여 $\mathrm{BER}(\mathrm{Bit}$ Error Rate)을 계산한다. $\mathrm{BER}$ 값 이 충분히 낮은 값이 되었을 경우(예, $\mathrm{BER}<10^{-4}$ )에는 $\mathrm{CRC}(\mathrm{Cyclic}$ Redundancy Code) 값을 계산하고, 부호화기 에서 전송받은 $\mathrm{CRC}$ 값과 비교하여 두 값이 일치하는 경우 에 채널 복호화 과정이 종료된다. 하지만, $\mathrm{BER}$ 값이 충분 히 낮은 값이 되지 않거나, 혹은 $\mathrm{BER}$ 값이 충분히 낮은 값
이 되더라도 이후 $\mathrm{CRC}$ 값이 일치하지 않는 경우에는 추가 적으로 패리티 전송을 요청한다. 결과적으로 이 두 가지는 채널 복호화의 종료 조건이라 말할 수 있다. 따라서 채널 복호화기는 종료 조건을 만족할 때까지 계속적으로 채널 복호화와 패리티 전송 요청의 과정을 반복한다.

\section{HDA 방법}

채널 부호 분야에서는 채널 복호 과정의 복잡도를 줄이 기 위해 여러 방법들이 제안되었는데, 그 중에서 $\mathrm{HDA}$ 방법 (경판정 출력을 이용한 고속 복호화)은 반복적인 계산으로 채널 복호 복잡도가 증가하는 점을 개선하기 위해 제안되 었다 ${ }^{[10]}$. LDPCA 부호는 확률적인 계산을 기반으로 반복적 인 복호 알고리듬을 수행하기 때문에 HDA 방법 적용이 용 이하다. HDA 방법은 복원된 비트플레인의 변화에 따라, 정 해진 최대 반복 횟수가 되기 전에 미리 채널 복호의 실패를 결정하는 방법이다. 즉, $\mathrm{LDPC}$ 복호 과정에서는 복호에 요 구되는 패리티의 양이 충분하지 않을 경우 복호된 경판정 결과값이 변하지 않는 특성을 가지고 있다. 따라서 $\mathrm{HDA}$ 방법은 복호 과정을 통해 매회 산출된 경판정 값 $(\mathrm{QCIF}$ 의 경우, 1584 개 모두)이 연속적으로 일정 횟수 (예, 10 회) 동 안 동일할 경우, 현재까지 전송된 패리티 비트만으로는 LDPCA 복호 과정이 성공할 수 없다고 미리 판단하는 방법 이다. 이렇게 연속적으로 동일한 경판정 값을 유지하는 반 복 (iteration) 횟수를 동일판정 연속 유지 횟수(이하 유지 횟수)라 한다. 이 유지 횟수가 외부에서 정한 특정 문턱치 (THD) 보다 커질 경우(이하 HDA 조건), 반복 복호 과정을 중단하고 추가 패리티 비트를 전송받는다. 반면에 이 유지 횟수가 특정 문턱치보다 작은 경우에는 반복 복호 과정을 기정의된 최대 횟수 만큼 유지한다. 따라서 $\mathrm{HDA}$ 방법은 복호 과정의 실패 유무를 조기에 결정하여 복호 과정의 반 복 횟수를 줄임으로써 시간 절감의 효과를 얻을 수 있다. 그림 1 은 여러 문턱치를 적용했을 경우의 $\mathrm{HDA}$ 방법의 결 과를 보여주고 있다. 그림 1 (a)는 패리티 전송에 따른 최대 50 회의 반복 복호 과정이 $\mathrm{HDA}$ 방법을 적용하였을 경우, 감소되는 복호 과정의 횟수를 나타내고 있다. $\mathrm{HDA} 10$ 은 문 턱치가 10 으로 설정된 $\mathrm{HDA}$ 방법을 적용한 경우를 의미하 


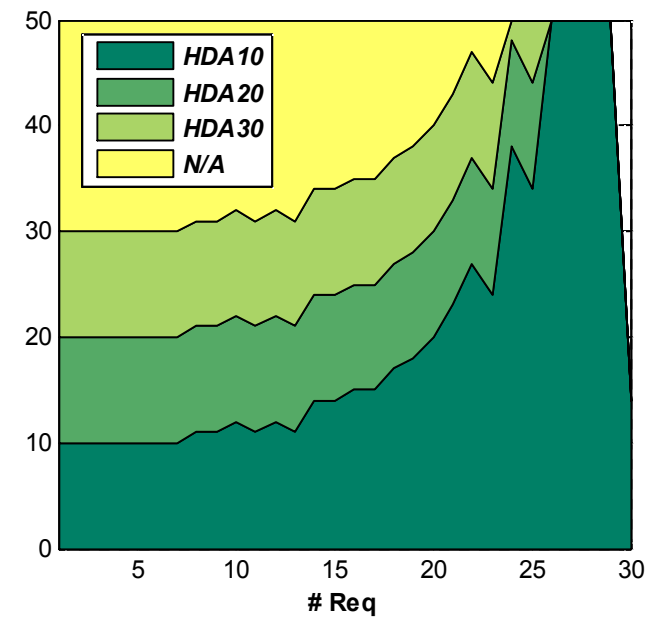

(a) 패리티요구량 대비 반복복호횟수

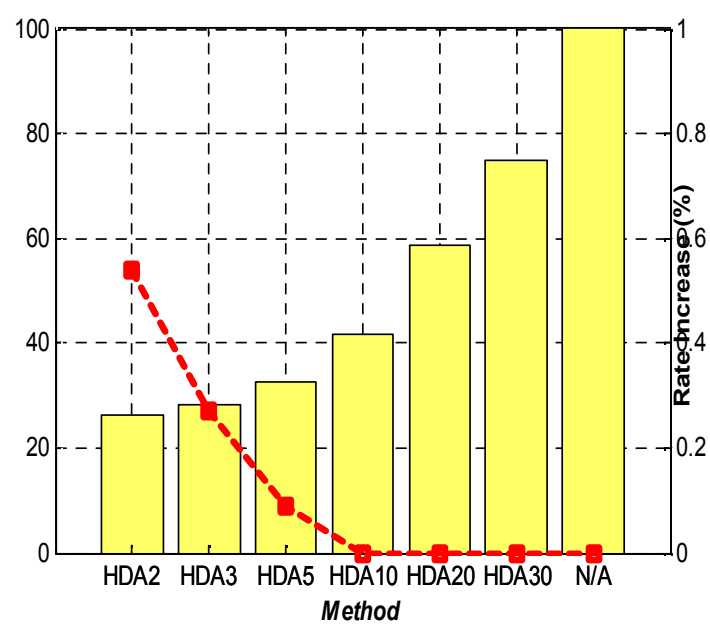

(b) 복호화 시간 비교

그림 1. HDA 계수 조절에 따른 복잡도 비교 (Foreman 영상, 첫 번째 프레임)

Fig. 1. HDA fast decoding method (1st frame, Foreman sequence)

며, $\mathrm{HDA} 30$ 에 비해 $\mathrm{HDA} 10$ 의 경우 반복 횟수가 상당히 감 소된다. 따라서 낮은 문턱치를 적용하는 것이 복호 과정의 복잡도를 줄이는데 더 효과적임을 알 수 있다. 그림 1 (b)에 서 보이고 있는 것은 각각 문턱치를 적용했을 때 얻어지는 정규화된 복호시간(막대그래프, 왼쪽 $\mathrm{y}$ 축)과 동시에 그에 따르는 패리티 요구량의 변화(실선, 오른쪽 $\mathrm{y}$ 축)이다. 그림 1 (b)에서 패리티 요구량(실선)을 보면 특정 문턱치 이하 (HDA10)를 적용했을 경우, 요구되는 패리티가 증가된다는 것을 알 수 있는데, 패리티 요구량이 증가하는 이유는 현재 의 패리티량이 복호화가 성공하기에 충분함에도 불구하고, $\mathrm{HDA}$ 의 문턱치에 따라 부족하다고 판단하기 때문이다. 따 라서 적절한 문턱치를 설정하지 못한 경우, 복잡도 절감 면 에서 이득이 크지 않거나, 율 왜곡 성능이 저하(패리티 요구 량 증가)될 가능성이 크다. 따라서 적정 문턱치는 각 영상의 특성에 따라 다르고 비트플레인의 위치에 따라서도 다르기 때문에, $\mathrm{HDA}$ 방법은 서로 다른 영상에 대하여 획일적으로 적용할 수 없는 단점을 가진다.

이러한 단점을 극복하기 위해 [9]에서는 적응적 $\mathrm{HDA}$ 방 법을 제안하였다. 제안방법에서는 특정 프레임의 LDPC 채 널 복호 과정에서 $\mathrm{HDA}$ 문턱치에 대한 특성을 밴드별, 비트 플레인별로 추출하는데, 문턱치에 대한 특성은 복호 과정 중 발생하는 유지 횟수에 대한 정보를 통해 얻어진다. 즉,
현재 비트 플레인의 유지 횟수가 기 정의된 후보 문턱치 집합 내에 포함 여부와 패리티 요구량에 따라서 결정된다. 이러한 기준을 활용하는 것은 패리티 요구량이 적은 비트 플레인에 낮은 유지 횟수 문턱치를 설정할 경우 율 왜곡 측면에서 손실이 큰 반면, 패리티 요구량이 많은 비트 플레 인에 낮은 문턱치를 설정하는 경우에는 율 왜곡 측면에서 손실이 작다는 특성에 기인한다. 이렇게 문턱치에 대한 특 성이 추출되면 시간적 상관도가 높은 이후 프레임에 문턱 치 특성을 반영하여 $\mathrm{HDA}$ 방법을 적용한다. 결과적으로 적 응적 $\mathrm{HDA}$ 방법은 여러 실험 영상에 실험적으로 선택된 최 적의 문턱치를 적용한 $\mathrm{HDA}$ 방법 대비 복잡도 절감 면에서 거의 유사한 성능을 가진다.

\section{III. 제안방법}

\section{1. 패리티 요구량 예측을 이용한 고속 복호화 방법}

이전 장에서 기술한 $\mathrm{HDA}$ 방법이나 적응적 $\mathrm{HDA}$ 방법의 경우는 결국 복잡도 절감의 문제를 그림 1 (a)에서 볼 수 있는 것처럼 복호 과정의 횟수 측면(y축)에서 접근한 방법 이라고 요약할 수 있다. 하지만 전체 $\mathrm{WZ}$ 복호화 과정의 복 


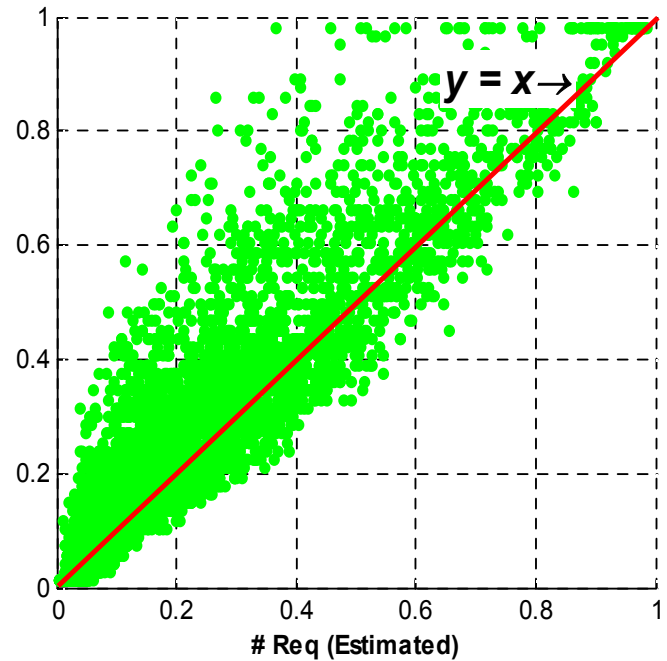

(a) 실제 대비 예측 패리티 요구량 (표준화됨)

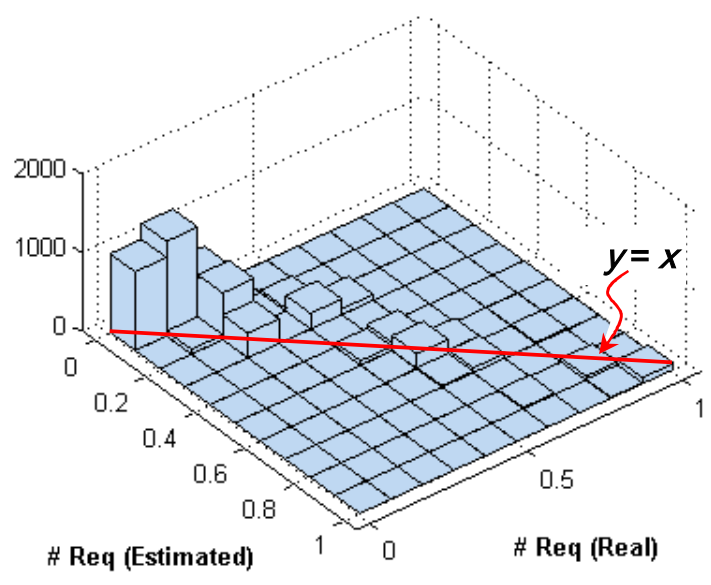

(b) 발생 횟수에 따른 히스토그램

그림 2. 실제 패리티 요구량 대비 엔트로피 기반 예측량 (Foreman 영상, 표준화됨)

Fig. 2. Real amount of parity requests vs. estimated requests by entropy (Foreman sequence, normalized)

잡도에서 LDPCA 복호 과정이 차지하는 비중은 여전히 높 다. 따라서 추가적으로 복잡도를 감소시킬 수 있는 알고리 듬이 요구되는데, 한 가지 접근 방법으로는 그림 1 (a)에서 패리티 요구량 측면(x축)에서도 복잡도 절감 방법을 적용 하는 것이다. 즉, $\mathrm{HDA}$ 방법은 현재 전송된 패리티에 대한 복호 과정의 횟수를 줄임으로써 고속 복호를 실현하는 방 법이다. 하지만 $\mathrm{HDA}$ 방법은 채널 복호가 성공하기에는 부 족한 만큼의 패리티 비트량에 대해서도 여전히 복호 과정 을 수행하고 있으며, 이러한 소모적인 과정을 줄이게 되면 추가적으로 복잡도를 낮출 수 있다. 따라서 제안하는 고속 채널 복호 방법은 고속 복호 성능을 높이기 위해 복호 과정 상의 복잡도 절감 방법과 패리티 요구량에 따른 복잡도 절 감 방법을 동시에 고려함으로써 전체적인 복잡도 절감의 효율을 높인다.

패리티의 요구량을 예측하는 가장 기본적인 방법은 채널 노이즈에 따른 엔트로피를 측정하는 것이다. 엔트로피는 연판정 입력으로 계산되는 LLR 값으로부터 구할 수 있다 ${ }^{[13]}$. 하지만 엔트로피에 의한 패리티 요구량 예측 방법은 채 널 노이즈의 정확도에 의존하기 때문에 부정확해지는 경우 가 많다. 즉, 패리티량의 정확한 예측은 채널 노이즈가 정확
히 계산되었을 경우를 제외하면 과대(혹은 과소)평가된다. 그림 2 (a)는 Foreman 영상의 경우 측정된 실제 패리티 요 구량과 엔트로피로 예측한 패리티 요구량의 관계를 보여주 고 있다. 예측이 정확한 경우에는 대부분의 점들이 $\mathrm{y}=\mathrm{x}$ 선 에 가깝게 모이겠지만, 실제로는 $\mathrm{y}=\mathrm{x}$ 선 주위에 넓게 분포 되어 있다. 이를 3 차원 히스토그램으로 보면 실제 발생되는 횟수에 대한 정보를 관찰할 수 있는데, 그림 2 (b)에서 보면 $\mathrm{y}=\mathrm{x}$ 선보다 기울기가 더 큰 영역(과소평가)에 발생 빈도가 높고, 또한 낮은 패리티 요구량일 경우에 발생 빈도가 높다 는 것을 확인할 수 있다.

요약하면, 채널 노이즈 모델를 통해 엔트로피를 구하여 패리티 요구량을 예측할 경우 실제 요구되는 패리티에 비 해 과소평가를 하는 경향이 크며, 발생 빈도는 낮더라도 예 측 결과가 $y=x$ 의 기울기에 비해 넓게 퍼져 있기 때문에 전 체적인 정확도가 떨어진다. 따라서 엔트로피에 의한 패리 티 요구량 예측은 이러한 단점을 보완하지 않으면 사용하 기 어렵다. 본 논문에서는 엔트로피를 대신할 수 있는 방법 으로 비트 플레인 간 상관도와 시간적 상관도를 동시에 이 용하여 패리티 요구량을 예측하는 방법을 제안한다. 


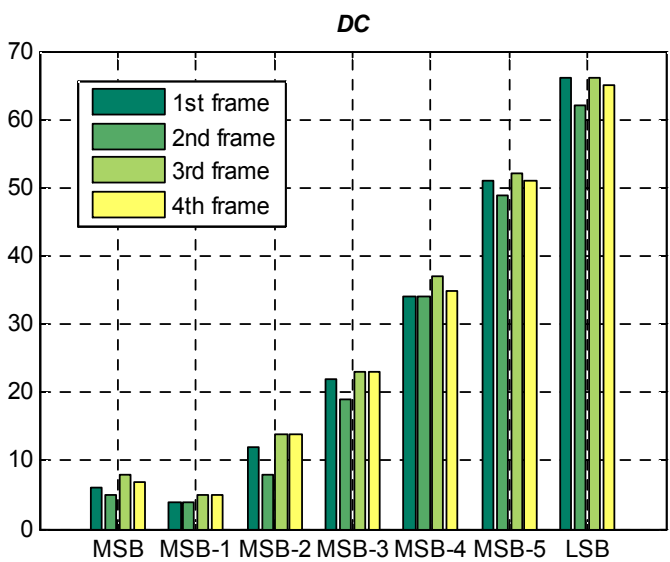

(a) 비트 플레인별 패리티 요구량 (DC)

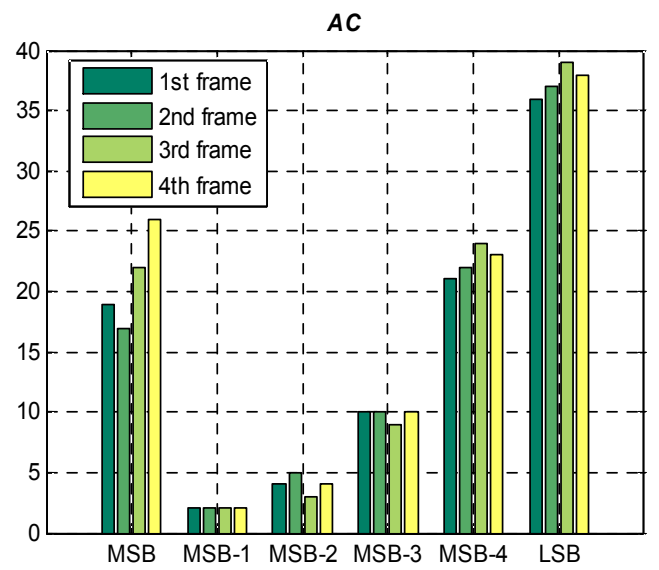

(b) 비트 플레인별 패리티 요구량 (AC1)

그림 3. 비트 플레인 및 시간에 따른 패리티 요구량 (Foreman 영상)

Fig. 3. Number of parity requests for bit planes and frames (Foreman sequence)

\section{1 비트 플레인의 상관도를 이용한 고속화 방법}

패리티 요구량의 예측 방법은 앞서 설명한 엔트로피에 의한 예측 방법과 같은 직접적인 방법과 간접적인 예측 방 법으로 나눌 수 있다. 간접적인 예측 방법은 실제로 계산하 는 방식이 아니라 현재 신호에 대한 정보를 유사하다고 가 정되는 주위 상황으로부터 유추하는 방식이며, 정확도 면

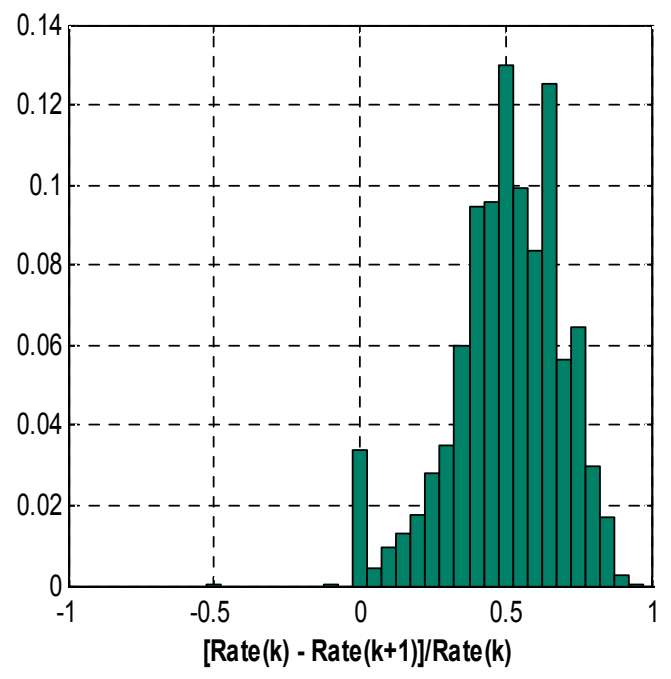

(a) 상위 비트 플레인과의 상대적인 율 차이
에서 문제가 없다면 아주 빠르게 예측할 수 있다. 이런 방법 중에 가장 간단한 방법은 비트 플레인 간 상관도를 활용하 는 방법이라 할 수 있다.

각각의 주파수 밴드는 복수 개의 비트 플레인으로 구성 되어 있으며, 보조 정보에 발생하는 채널 노이즈는 비트 플 레인이 $\mathrm{LSB}$ 로 갈수록 증가한다. 그림 3 은 $\mathrm{DC}$ 와 $\mathrm{AC1}$ 의 비

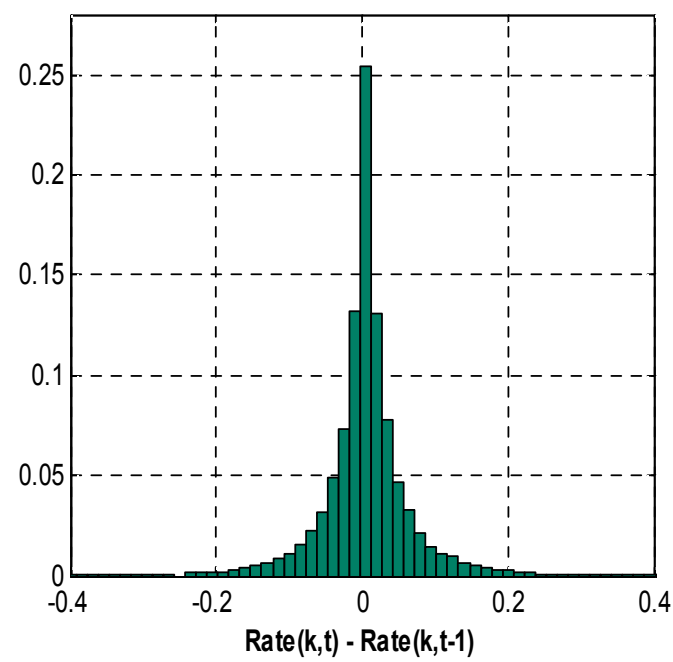

(b) 이전프레임의 비트 플레인과의 절대적인 율 차이

그림 4. 비트 플레인 상관도에 따른 패리티 요구량 차이(mobile, mother and daughter, salesman, akiyo 영상, 전체 주파수 밴드, 전체 비트플레인, 율은 표준화됨)

Fig. 4. Difference of parity requests for bit planes and previous frames (mobile, mother and daughter, salesman, akiyo sequences, total frequency band, total bitplane, rate is normalized) 
트 플레인에 따른 패리티 요구량을 보여주고 있으며, MSB 에서 LSB로 갈수록 채널 노이즈가 증가하기 때문에 LSB 로 갈수록 많은 패리티가 요구되는 것을 볼 수 있다. 이는 보조 정보가 원 정보와 동일할 확률이 $\mathrm{LSB}$ 로 갈수록 $1 / 2$, $1 / 4,1 / 8, \ldots$ 등 기하급수적으로 줄어들기 때문이다. 따라서 상위 비트 플레인의 패리티 요구량은 현재 비트 플레인에 대한 하계(lower bound)가 되기 때문에 현재 비트 플레인에 대한 최소 패리티 요구량을 예측할 수 있게 된다. 이렇게 패리티 요구량을 예측할 경우에는 예외가 생기는데, MSB 와 바로 아래 MSB-1 비트 플레인의 경우에는 패리티 요구 량 하계 조건을 적용할 수 없다. $\mathrm{AC}$ 의 경우에는 $\mathrm{MSB}$ 가 부호(sign) 비트이고 MSB-1부터는 크기(magnitude)에 해 당하기 때문에 패리티 요구량 사이에 상관관계가 없다. DC 의 경우 MSB와 MSB-1에 대해 패리티 요구량이 오히려 감 소하는 것은 $\mathrm{MSB}$ 의 경우에는 독립 복호를 통해 복호화 과 정을 수행하지만, MSB-1은 독립 복호가 아닌 MSB의 복호 화 결과를 이용한 결합 복호(joint decoding)를 수행하기 때 문이다 ${ }^{[11]}$. 따라서 이 두 가지 예외 경우를 제외하면 패리 티 요구량 하계 조건은 언제나 적용할 수 있다. 이렇게 하계 조건을 적용하였을 경우는 그림 4 (a)에서 관찰할 수 있다. 그림 4 (a)는 모든 주파수 밴드에 대해서 MSB와 MSB-1을 제외한 나머지 비트 플레인들에 대해 상대적인 율의 차이를 구한 뒤 발생확률을 나타낸 것이다. 상대적 인 율의 차이는 (현재 비트플레인의 율 - 상위 비트플레인 의 율)/현재 비트플레인의 율로 계산하였다. 그림에서 확 인할 수 있는 것처럼 거의 대부분의 경우, 상위 비트 플레 인의 율이 현재 비트 플레인의 율보다 크거나 같기 때문 에 양수 방향의 분포를 가지는 것을 알 수 있으며, 0 보다 작은 경우는 $0.01 \%$ 정도에 불과하다. 또한 분포의 평균은 0.5 정도이기 때문에 패리티 요구량 하계 조건을 적용할 경우, 현재 비트 플레인에 소요되는 율의 평균 $50 \%$ 정도 수준을 예측할 수 있다.

1.2 패리티 요청량의 시간적 상관도를 이용한 고속화 방법 비트 플레인의 상관도와 함께 이용할 수 있는 방법은 시 간적 상관도를 이용하는 방법이다. 일반적으로 이웃한 프 레임의 동일 밴드, 동일 비트 플레인 간에는 일정한 시간적
상관성을 가지고 있기 때문에 현재 비트 플레인의 패리티 요구량에 대한 정보를 유추할 수 있다. 그림 3 에서 볼 수 있는 것처럼 연속적인 4 개의 $\mathrm{WZ}$ 프레임의 경우 동일위치 비트 플레인의 패리티 요구량이 서로 큰 차이를 보이지 않 고 상관성을 보인다. 영상이 높은 시간적 상관성을 가진다 면 실제 패리티 요구량과 예측량 간의 차이에 대한 기대치 (expectation)는 ' 0 '으로 수렴한다. 그림 4 (b)는 이전 프레 임의 동일 주파수 밴드, 동일 위치 비트 플레인의 율과 현재 비트 플레인의 율의 차이를 발생 확률로 나타낸 그래프이 다. 평균이 0 으로 수렴하는 것을 확인할 수 있으며, -0.1 0.1 (최대 65회 패리티를 요구할 수 있는 1584 길이 LDPCA 부호의 경우, 0.1 은 대략 7회 정도의 패리티 요구량임) 사이 에 발생하는 확률이 $90 \%$ 정도이다. 따라서 시간적 상관도 를 활용하는 것이 유용할 수 있음을 파악할 수 있다. 하지만 여전히 예측량과 차이가 많이 나는 경우가 발생하는 것을 볼 수 있기 때문에 이러한 부분을 해결해야 한다. 예측량의 과대 혹은 과소평가는 압축 성능에 영향을 미치게 되는데, 그 중 실제 패리티 요구량보다 큰 값으로 예측했을 경우(과 대평가)는 율을 증가시키기 때문에 전체 압축 성능이 저하 된다. 따라서 과대평가에 대한 부분을 보완해야할 필요성 이 있다. 하지만 시간적 상관도에 의한 예측 방법을 추가적 인 알고리듬을 통해 보완하는 것은 결국 새로운 복잡도 증 가를 초래하게 되며, 이는 본 논문의 원래 목적인 복호 과정 의 고속화와 모순이 된다. 따라서 제안 방법은 전술한 패리 티 요구량 하계 조건을 활용하여 시간적 상관도에 따른 예 측량을 보완하기 위해 식 (2)과 같이 패리티 요구량을 예측 한다.

$$
E_{t}^{b, k}=\left(R_{t-1}^{b, k}+R_{t}^{b, k+1}\right) \gg 1
$$

식 (2)에서 $E$ 는 복호 시작 시 전송받을 패리티의 예측량, $R$ 은 해당 비트 플레인의 패리티 요구량이다. 또한 $b, k, t$ 는 각각 주파수 밴드, 비트 플레인, 프레임의 번호를 나타내며, 》는 오른쪽 쉬프트(right shift) 연산을 의미한다. 결과적으 로 한 비트 플레인을 복호할 때 복호 과정을 생략할 수 있는 패리티 예측량 $E$ 는 이전 프레임의 동일 위치 비트 플레인 의 최종 패리티 요구량과 동일 주파수 밴드 내 상위 비트 플레인의 최종 패리티 요구량의 평균값이다. 이렇게 계산 


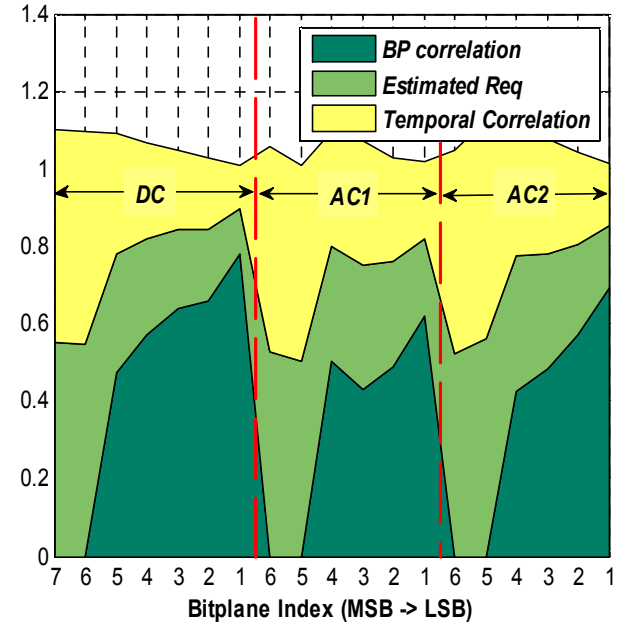

(a) 비트 플레인별 상관도에 따른 패리티 예측량

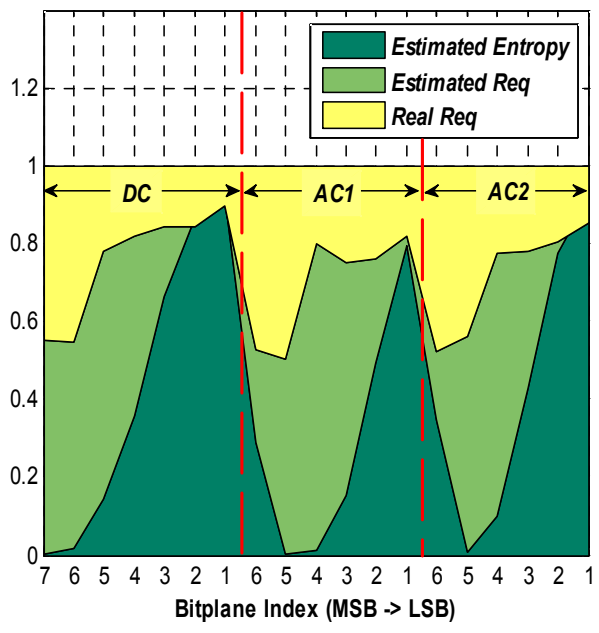

(b) 엔트로피에 의한 패리티 예측량

그림 5. 패리티 예측량 및 실제 패리티 요구량 비교 (Foreman 영상)

Fig. 5. Comparison of estimated and real amount of parity bits (Foreman sequence)

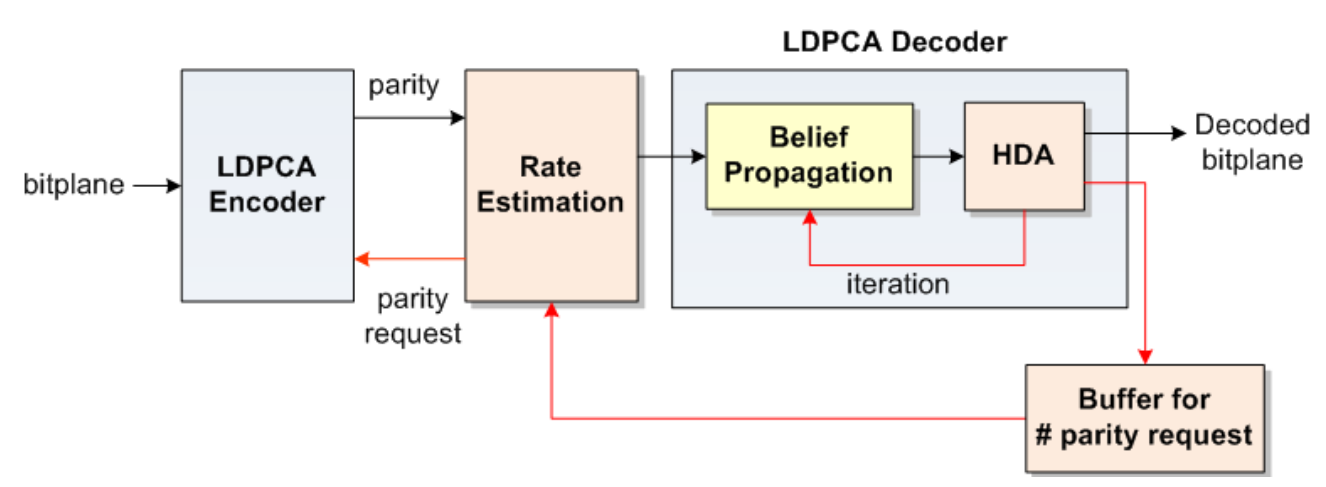

그림 6. 제안 방법의 블록 다이어그램

Fig. 6. Block diagram of the proposed method

된 패리티 예측량은 LDPC 복호 시에 초기 패리티 요구량 으로 설정되며, 이 초기값으로 LDPC 복호가 성공하지 못 할 경우에는 이 초기값으로부터 점진적으로 패리티 요구량 을 늘리며 복호를 실행한다. 그림 5는 패리티 예측량 대비 실제 패리티 요구량의 비(ratio)를 나타낸 그림으로, 제안 방법은 그림 5 (a)에서 볼 수 있는 것처럼 시간적 상관도에 의한 예측량과 비트 플레인의 상관도를 이용한 하계 예측 량의 중간에 위치하게 된다. 그림 5 (b)의 그림은 엔트로피 에 의한 예측량과 제안 방법과의 차이를 보여주고 있는데, 엔트로피로 구한 예측량은 MSB로 갈수록 상당히 과소평 가하는 경향을 보이는 반면, 제안 방법은 실제 패리티 요구
량의 60 80\% 정도까지 예측하고 있다는 것을 알 수 있다. 제안 방법의 가장 큰 장점은 패리티 예측을 수행하는 과정 에서 증가하는 복잡도가 아주 낮다는 것이다. 식 (2)에서 보면 제안 방법은 상위 비트 플레인에 대한 패리티 요구량 과 이전 프레임의 동일 위치에 대한 패리티 요구량에 대한 메모리, 그리고 하나의 덧셈 연산과 하나의 쉬프트(shift) 연 산을 요구한다. 이러한 간단한 연산으로 실제 패리티 요구 량 대비 평균 $70 \%$ 정도의 복호 과정을 생략할 수 있기 때문 에 시간 절감의 효과를 갖는다. 제안 방법에 대한 블록 다이 어그램은 그림 6 과 같다. 


\section{IV. 실험 및 결과}

\section{1. 실험 방법}

본 논문에서는 제안 방법의 성능을 평가하기 위하여 각 각 150 프레임의 Foreman, Stefan, Coastguard, Hall monitor 영상을 사용하여 실험하였다. 영상들의 크기는 QCIF, 프레임 율은 $15 \mathrm{~Hz}$ 이다. 양자화 행렬은 $1,5,7,8$ 에 대해서 실 험하였으며 ${ }^{[12]}$, 상응하는 키 프레임의 QP값으로 Foreman, Stefan 영상은 40,34, 29, 25, Coastguard 영상은 38, 33, 30,26 , 그리고 Hall monitor 영상은 $37,33,29,24$ 를 설정 하여 실험하였다. LDPC 부호는 [4]에서 제안한 LDPCA 부 호를 사용하였으며, 성능 비교는 $\mathrm{WZ}$ 프레임에 한해서 이 루어졌다.

비교 대상은 영상에 따라 최적으로 선택된 문턱치를 이 용한 $\mathrm{HDA}$ 방법과 제안 방법, 그리고 제안 방법과 $\mathrm{HDA}$ 를 동시에 적용한 방법이며, 추가적으로 제안 방법은 두 가지 방법으로 나누어서 실험을 수행하였다. 따라서 실험을 수 행한 고속화 방법은 총 5 가지이며, 각각의 방법은 다음과 같다.

· HDA : HDA를 적용한 방법 ${ }^{[10]}$

- M1 : 비트 플레인의 상관도를 이용한 방법 (패리티 요 구량 하계조건)

- M2 : 비트 플레인의 상관도와 시간적 상관도를 동시에 이용한 방법 (식 (2))

- $\mathrm{M} 1+\mathrm{HDA}$ : $\mathrm{M} 1$ 과 $\mathrm{HDA}$ 를 동시에 적용한 방법

$\cdot \mathrm{M} 2+\mathrm{HDA}$ : $\mathrm{M} 2$ 와 $\mathrm{HDA}$ 를 동시에 적용한 방법

HDA 방법의 경우 적용된 문턱치는 Foreman, Stefan, Coastguard, Hall monitor에 대해 각각 6, 5, 7, 9이다. 문턱 치를 선택한 방법은 각각의 영상에 여러 문턱치를 적용한 결과들 중 $\mathrm{BDPSNR}^{[14]}$ 이 $0.001 \mathrm{~dB}$ 이하인 것을 선택하였 다. $\mathrm{HDA}$ 방법은 모든 비트 플레인에 적용한 반면, 제안 방 법인 $\mathrm{M} 1$ 과 $\mathrm{M} 2$ 의 경우에는 각 주파수 밴드의 $\mathrm{MSB}$ 와 MSB-1 비트 플레인에는 패리티 요구량 하계 조건을 적용 할 수 없기 때문에 MSB-2에서 LSB까지의 비트 플레인에
대해서만 적용하였다. 실험은 각 방법에 대하여 시간 절감 율과 율 왜곡 성능을 보여주는 BDPSNR을 계산하였다.

\section{2. 실험 결과}

표 1 은 5 가지 방법에 대한 결과를 보여준다. 표 1 (b)와 (c)에서 $\mathrm{TSLDPC}$ 와 $\mathrm{TStotal}$ 은 각각 $\mathrm{LDPC}$ 복호 과정 자체 의 시간 절감율 (TS : Time Saving)과 전체 $\mathrm{WZ}$ 복호화 과 정에 대한 시간 절감율이다. 시간 절감율 $\mathrm{TS}$ 는 식 (3)와 같 이 계산한다.

$$
T S=\frac{T_{\text {org }}-T_{\text {fast }}}{T_{\text {org }}} \times 100
$$

여기서 $T_{o r g}$ 는 고속화 방법을 적용하지 않은 일반적인 복 호 방법인 경우, $T_{\text {fast }}$ 는 고속화 방법을 사용한 경우 복호화 과정 완료 시까지 걸린 시간을 나타낸다.

일단 율 왜곡 성능을 살펴보면, $\mathrm{HDA}$ 는 평균적으로 $0.0057 \mathrm{~dB}$ 정도의 성능 저하를 보이고 있으나 일반적으로 비디오 부호화에서는 $0.1 \mathrm{~dB}$ 이하의 성능 저하는 감내할 만한 수준으로 판단하고 있으므로, $0.01 \mathrm{~dB}$ 정도의 성능 저 하는 성능 차이가 거의 없다고 판단할 수 있다. 따라서 $\mathrm{HDA}$ 를 적용한 결과는 성능 저하가 거의 없는 수준이라고 할 수 있다. 패리티 요구량 하계 조건을 적용한 $\mathrm{M} 1$ 의 경우 에는 $\mathrm{HDA}$ 보다 작은 $0.0024 \mathrm{~dB}$ 정도로 성능 저하가 거의 없다. 반면, 식 (2)를 적용한 $\mathrm{M} 2$ 는 성능 저하가 $0.022 \mathrm{~dB}$ 까 지 증가한다. 이것은 비트 플레인의 상관도의 경우 그림 4 (a)에서 볼 수 있는 것처럼 예측량이 실제 요구량을 넘어서 는 경우가 드문 반면, 시간적 상관도의 경우에는 발생 확률 은 낮지만 여전히 낮은 상관도를 가지는 비트 플레인이 존 재하기 때문이다. 그림 1 (a)에서 $\mathrm{HDA}$ 는 $\mathrm{y}$ 축으로 고속화를 실현하는 반면, 제안 방법은 $\mathrm{x}$ 축으로 고속화를 실현하기 때 문에 두 가지 고속화 방법은 동시 적용이 가능하다. $\mathrm{M} 1+$ $\mathrm{HDA}$ 의 경우 $\mathrm{BDPSNR}$ 이 0.008 정도로 성능 저하가 거의 없다고 판단할 수 있으며, $\mathrm{M} 2+\mathrm{HDA}$ 의 경우에는 평균적으 로 $\mathrm{M} 2$ 보다 조금 더 성능 저하를 가지는 $0.0275 \mathrm{~dB}$ 정도이 다. 하지만 이정도의 성능 저하는 앞서 기술한 것과 같이 
표 1. 제안 방법의 실험 결과

Table 1. Experimental results of proposed method

(a) BDPSNR

\begin{tabular}{cccccc}
\hline \multirow{2}{*}{ Sequence } & \multicolumn{5}{c}{ BDPSNR [dB] } \\
\cline { 2 - 6 } & HDA & M1 & M2 & M1+HDA & M2+HDA \\
\hline Stefan & -0.0064 & -0.0034 & -0.0163 & -0.0098 & -0.0226 \\
\hline Foreman & -0.0039 & -0.0006 & -0.0303 & -0.0046 & -0.0340 \\
\hline Coastguard & -0.0064 & -0.0038 & -0.0365 & -0.0097 & -0.0423 \\
\hline Hall monitor & -0.0062 & -0.0016 & -0.0049 & -0.0077 & -0.0109 \\
\hline Average & -0.0057 & -0.0024 & -0.0220 & -0.0080 & -0.0275 \\
\hline
\end{tabular}

(b) LDPC 복호 과정에 대한 시간 절감율

\begin{tabular}{cccccc}
\hline \multirow{2}{*}{ Sequence } & \multicolumn{5}{c}{ TSLDPC (\%) } \\
\cline { 2 - 6 } & HDA & M1 & M2 & M1+HDA & M2+HDA \\
\hline Stefan & 63.31 & 32.06 & 44.85 & 68.92 & 72.67 \\
\hline Foreman & 56.70 & 33.17 & 47.00 & 63.72 & 69.11 \\
\hline Coastguard & 61.70 & 30.03 & 47.07 & 68.30 & 72.93 \\
\hline Hall monitor & 62.50 & 29.91 & 50.63 & 68.84 & 74.36 \\
\hline Average & 61.05 & 31.29 & 47.39 & 67.45 & 72.27 \\
\hline
\end{tabular}

(c) 영상 복호화 과정에 대한 시간 절감율

\begin{tabular}{cccccc}
\hline \multirow{2}{*}{ Sequence } & \multicolumn{5}{c}{ TStotal (\%) } \\
\cline { 2 - 6 } & HDA & M1 & M2 & M1+HDA & M2+HDA \\
\hline Stefan & 52.19 & 27.06 & 37.61 & 57.14 & 60.37 \\
\hline Foreman & 45.59 & 26.93 & 38.18 & 51.49 & 55.84 \\
\hline Coastguard & 45.44 & 22.16 & 34.84 & 50.33 & 53.83 \\
\hline Hall monitor & 38.06 & 18.91 & 31.65 & 42.32 & 45.76 \\
\hline Average & 45.32 & 23.77 & 35.57 & 50.32 & 53.95 \\
\hline
\end{tabular}

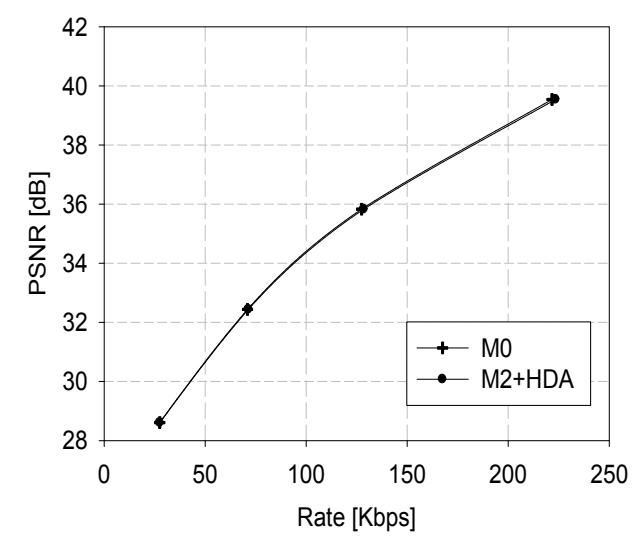

(a) Foreman 영상

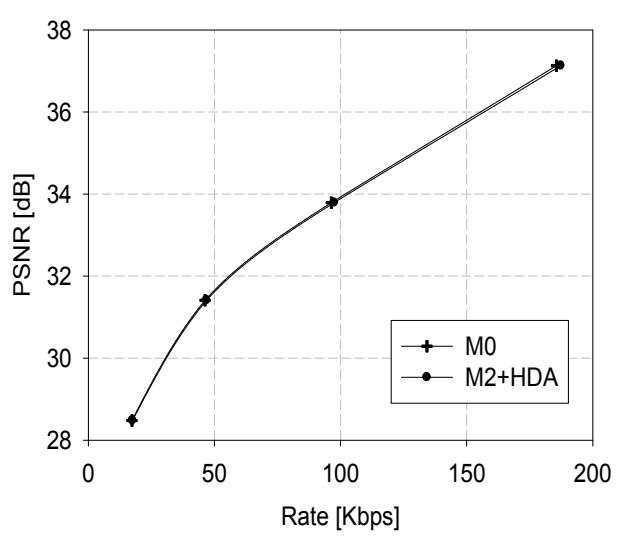

(b) Coastguard 영상

그림 7. 제안 방법의 율 왜곡 성능

Fig. 7. Rate Distortion performance of the proposed method

성능 상 크게 차이가 나지 않는다고 볼 수 있으며, 율 왜곡 성능 그래프로 보면 그림 7과 같다. 그림 7에서 두 개의 율
왜곡 성능 그래프는 표 1의 (a)에서 성능 저하가 가장 큰, $\mathrm{M} 2+\mathrm{HDA}$ 가 적용된 Foreman, Coastguard 영상에 대한 그 
래프이다. 또한 여기서 $\mathrm{M} 0$ 는 고속화 방법을 적용하지 않은 복호화 방법을 말한다. 표 1에서는 Foreman과 Coastguard 영상의 BDPSNR이 각각 $0.034 \mathrm{~dB}, 0.0423 \mathrm{~dB}$ 의 성능 저하 를 나타내고 있지만 실제 그래프 상으로는 큰 차이를 보이 지 않는다.

$\mathrm{LDPC}$ 복호 과정에 대한 시간 절감율을 살펴 보면 M1, $\mathrm{M} 2$ 는 각각 $31 \%$ 와 $47 \%$ 정도로 $\mathrm{HDA}$ 의 $1 / 2$ 과 $3 / 4$ 정도 수 준인 것을 볼 수 있다. 이전 장에서 $\mathrm{M} 1$ 의 경우 약 $50 \%$ 의 시간 절감율을, $\mathrm{M} 2$ 의 경우 약 $70 \%$ 의 시간 절감율을 가질 것으로 분석한 것에 비해 실험 결과가 현저히 낮은 이유는 제안 방법을 적용한 비트 플레인의 개수가 적기 때문이다. 즉, 제안 방법은 MSB와 MSB-1 비트 플레인을 제외한 나 머지 비트 플레인에만 적용하며, QM 1, 5, 7,8에서 제안 방법이 적용되는 비트 플레인의 비율은 각각 $40 \%, 28 \%$, $40 \%, 52 \%$ 로 상당히 낮다. 따라서 평균적으로 $40 \%$ 의 비트 플레인에만 $\mathrm{M} 1, \mathrm{M} 2$ 를 적용한 결과이기 때문에 모든 비트 플레인에 적용되는 $\mathrm{HDA}$ 에 비해 시간 절감율이 떨어진다. 따라서 전체 비트 플레인의 반 이상을 차지하는 MSB, MSB-1 비트 플레인에 대한 정확한 패리티 요구량 예측 방 법을 연구하는 것이 의미를 가진다고 할 수 있다. 제안 방법 은 독립적인 적용보다는 $\mathrm{HDA}$ 를 보완하는 방법으로서 더 큰 의미를 가지기 때문에 $\mathrm{HDA}$ 와 동시에 적용된 방법을 살 펴보아야 한다. $\mathrm{M} 1+\mathrm{HDA}$ 의 경우는 $67 \%$ 정도로 $\mathrm{HDA}$ 보다 $6 \%$ 정도 더 시간절감을 가지며, $\mathrm{M} 2+\mathrm{HDA}$ 의 경우는 약 $72 \%$ 로 $\mathrm{HDA}$ 에 비해 $11 \%$ 정도 더 $\mathrm{LDPC}$ 복호 시간을 절감 할 수 있다. 표 1의 (c)에서는 전체 복호화 과정에 대한 시간 절감율은 $\mathrm{HDA}$ 가 약 $45 \%$ 를 절감하는데 반해, $\mathrm{M} 1+\mathrm{HDA}$ 와 $\mathrm{M} 2+\mathrm{HDA}$ 는 각각 $5 \%$ 와 $8 \%$ 정도의 추가적인 시간 절감율 을 가짐으로 인해 전체 $50 \%$ 정도의 복호화 시간을 절감할 수 있는 것을 볼 수 있다. LDPC 복호 이외의 복잡도 중 가장 높은 비중을 차지하는 것은 보조정보를 생성할 때 반 복적으로 수행되는 움직임 예측 과정이다. 특히, 본 실험에 사용된 움직임 예측 과정은 전영역 움직임 예측(Full Search Motion Estimation)을 사용했기 때문에 전체 복호화 시간에 대한 시간 절감율이 떨어진다. 따라서 보조정보 생 성 시의 움직임 예측의 고속화 방법에 대해서도 추가적인 연구가 필요하다.

\section{V. 결 론}

본 논문에서는 $\mathrm{HDA}$ 방법과 동시에 패리티 요구량의 예 측 방법을 이용한 분산 비디오 부호화 기술의 고속 복호화 방법을 제안하였다. HDA 방법은 주어진 패리티 요구량에 대해 반복 복호 횟수를 최소화하며 동시에 율 왜곡 성능을 유지할 수 있는 장점을 가지고 있는데, 제안 방법은 $\mathrm{HDA}$ 와 병행하여 적용할 수 있기 때문에 $\mathrm{HDA}$ 의 장점을 그대로 유 지할 수 있다. 따라서 $\mathrm{HDA}$ 와 제안 방법을 동시에 적용 (M2+HDA) 시 실험적으로 얻어진 최적의 문턱치를 적용한 $\mathrm{HDA}$ 방법 대비 $11 \%$ 정도의 LDPC 복호시간을 절감할 수 있으며, BDPSNR은 $0.0275 \mathrm{~dB}$ 정도의 저하로 율 왜곡 성 능이 크게 저하되지 않았다. 패리티 요구량 예측 시 필요한 연산은 덧셈 연산 하나와 쉬프트 연산 하나만으로 이루어 져 있기 때문에 최소 연산량으로 추가적인 시간 절감을 얻 을 수 있다는 점이 제안 방법이 가진 가장 큰 장점으로 꼽을 수 있다. 하지만 제안 방법이 적용되는 비트 플레인이 전체 비트 플레인의 $50 \%$ 이하이기 때문에 향후 MSB와 MSB- 1 비트 플레인의 패리티 요구량 예측에 대한 추가 연구가 필 요하다.

\section{참 고 문 헌}

[1] A. Aaron, R. Zhang, and B. Girod, "Wyner-Ziv Coding of Motion Video," Asilomar Conference on Signals, Systems and Computers, pp. 240-244, Pacific Grove, CA, USA, November 2002.

[2] R. Puri and K. Ramchandran, "PRISM: A New Robust Video Coding Architecture Based on Distributed Compression Principles," 40th Allerton Conference on Communication, Control and Computing, pp. 1-10, Allerton, USA, October 2002.

[3] F. Pereira, C. Brites, J. Ascenso, and M. Tagliasacchi, "Wyner-Ziv video coding: A review of the early architectures and further developments," IEEE Intl. Conf. on Multimedia and Expo, pp. 625-628, Hannover, Germany, June 2008.

[4] D. Varodayan, A. Aaron, and B. Girod, Rate-adaptive codes for distributed source coding, EURASIP Signal Processing Journal, Special Section on Distributed Source Coding, Vol. 86, no. 11, pp. 3123-3130, November 2006.

[5] J. Ascenso, C. Brites, and F. Pereira, "Improving frame interpolation with spatial motion smoothing for pixel domain distributed video coding," 5th EURASIP Conf. on Speech and Image Processing, Multimedia Communications and Services, Smolenice, Slovak Republic, June 2005. 
[6] 고봉혁, 심혁재, 전병우, “복호 신뢰도에 기반하여 점진적으로 보조정보 를 향상시키는 변환영역 Wyner-Ziv 부호화 방법”, 방송공학회논문지, 제 13권 제6호 892 904쪽, 2008년 11월.

[7] 심혁재, 전병우, “분산 비디오 압축 기술”, 전자공학회지, 제 36 권 4호, 91-105쪽, 2009년 4월.

[8] http://www.img.lx.it.pt/ discover/home.html

[9] 오량근, 심혁재, 전병우, "적응적 경판정 출력을 이용한 고속 분산 비디오 복호화 기술”, 대한전자공학회논문지, 제 47권, $\mathrm{SP}$ 편, 제6호, 66 74쪽, 2010년 11월.

[10] R. Y. Shao, S. Lin and M. P. C. Fossorier, "Two simple stopping criteria for turbo decoding," IEEE Trans. Comm, vol. 47, pp. 1117-1120, Aug. 1999.
[11] R. P.Westerlaken, S. Borchert, R. K. Gunnewiek, and R. L. Lagendijk, "Analyzing symbol and bit plane-based LDPC in distributed video coding," In Proc. Int'l Conf. Image Processing (ICIP), 2007.

[12] C. Brites, J. Ascenso and F. Pereira, "Improving transform domain Wyner-Ziv coding performance," IEEE International Conf. on Acoustics, Speech and Signal Processing, pp. 525-528, Toulouse, France, May 2006.

[13] C. Brites, F. Pereira, "Encoder Rate Control for Transform Domain Wyner-Ziv Video Coding", Int. Conf. on Image Processing (ICIP'2007), San Antonio, TX, USA, Sep. 2007.

[14] G. Bjontegaard, "Calculation of Average PSNR Differences Between RD-curves", document VCEG-M33, ITU-T Video Coding Experts Group (VCEG) Meeting, Austin, TX, Apr. 2-4, 2001.

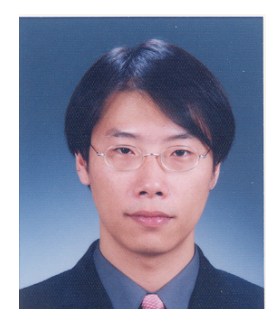

\section{심 혁 재}

- 2000년 : 성균관대학교 전자공학과 졸업 (학사)

- 2002년 : 성균관대학교 정보통신공학부 졸업 (석사)

- 2002년 현재 : 성균관대학교 정보통신공학부 박사과정

- 주관심분야 : 멀티미디어 영상압축, 신호처리

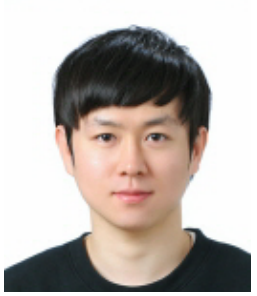

\section{오 양 근}

- 2009년 : 성균관대학교 정보통신공학부 졸업 (학사)

- 2009년 2011년 : 성균관대학교 정보통신공학부 졸업 (석사)

- 2011년 현재 : 삼성전자 무선 사업부

- 주관심분야 : 멀티미디어 영상압축, 신호처리

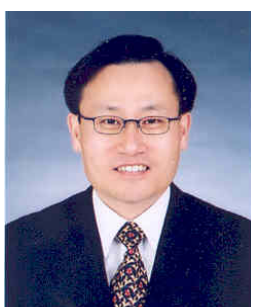

\section{전 병 우}

- 1985년 : 서울대학교 전자공학과 졸업 (학사)

- 1987년 : 서울대학교 전자공학과 졸업 (석사)

- 1992년 : Purdue Univ, School of Elec. 졸업 (공학박사)

- 1993년 1997년 : 삼성전자 신호처리연구소 수석연구원

- 1997년 현재 : 성균관대학교 정보통신공학부 교수

- 주관심분야 : 멀티미디어 영상압축, 영상인식, 신호처리 